\title{
The structural performance of near-optimized truss core panels
}

\author{
S. Chiras ${ }^{\text {a,* }}$, D.R. Mumm ${ }^{\text {a }}$, A.G. Evans ${ }^{\text {a }}$, N. Wicks ${ }^{\text {b }}$, J.W. Hutchinson ${ }^{\text {b }}$, \\ K. Dharmasena ${ }^{\mathrm{c}}$, H.N.G. Wadley ${ }^{\mathrm{c}}$, S. Fichter ${ }^{\mathrm{d}}$ \\ ${ }^{a}$ Princeton Materials Institute, Princeton University, Princeton, NJ 08534, USA \\ ${ }^{\mathrm{b}}$ Division of Engineering and Applied Sciences, Harvard University, Cambridge, MA 02138, USA \\ ${ }^{\mathrm{c}}$ Department of Materials Science and Engineering, University of Virginia, Charlottesville, VA 22903, USA \\ d Aurora Casting \& Engineering, Inc., Santa Paula, CA 93050, USA \\ Received 11 April 2001; received in revised form 3 January 2002
}

\begin{abstract}
Theoretical studies have indicated that truss core panels with a tetragonal topology support bending and compression loads at lower weight than competing concepts. The goal of this study is to validate this prediction by implementing an experimental protocol that probes the key mechanical characteristics while addressing node eccentricity and structural robustness. For this purpose, panels have been fabricated from a beryllium-copper alloy using a rapid prototyping approach and investment casting. Measurements were performed on these panels in flexure, shear and compression. Numerical simulations were conducted for these same configurations. The measurements reveal complete consistency with the stiffness and limit load predictions, as well as providing a vivid illustration of asymmetric structural responses that arises because the bending behavior of optimized panels is dependent on truss orientation. () 2002 Elsevier Science Ltd. All rights reserved.
\end{abstract}

Keywords: Ultralight; Octet-truss; Periodic; Sandwich panels; Multifunctional

\section{Introduction}

Truss core panels have been identified as candidates for ultra-light structures that experience predominantly bending or compressive loads (Wicks and Hutchinson, 2001; Wallach and Gibson, (in press); Deshpande et al., 2001; Evans et al., 2001; Deshpande and Fleck, 2001). Theoretical results have explored truss core and face member topologies that realize the minimum weights. These preferred designs require that, in regions where the core experiences shear, the trusses experience only compression or tension (no bending). The octet truss topology has this characteristic (Fuller, 1961). The unit cell for the core is depicted in Fig. $1 b$ and the plan view in Fig. 1a.

The shear stress/strain response of the octet truss core is slightly anisotropic (Wicks and Hutchinson, 2001; Deshpande et al., 2001; Deshpande and Fleck, 2001), differing in the responses exhibited by panels

\footnotetext{
${ }^{*}$ Corresponding author. Tel.: +1-914-945-3994; fax: +1-914-945-3623.

E-mail address: chiras@us.ibm.com (S. Chiras).
} 


\section{a Plan View Of Core}
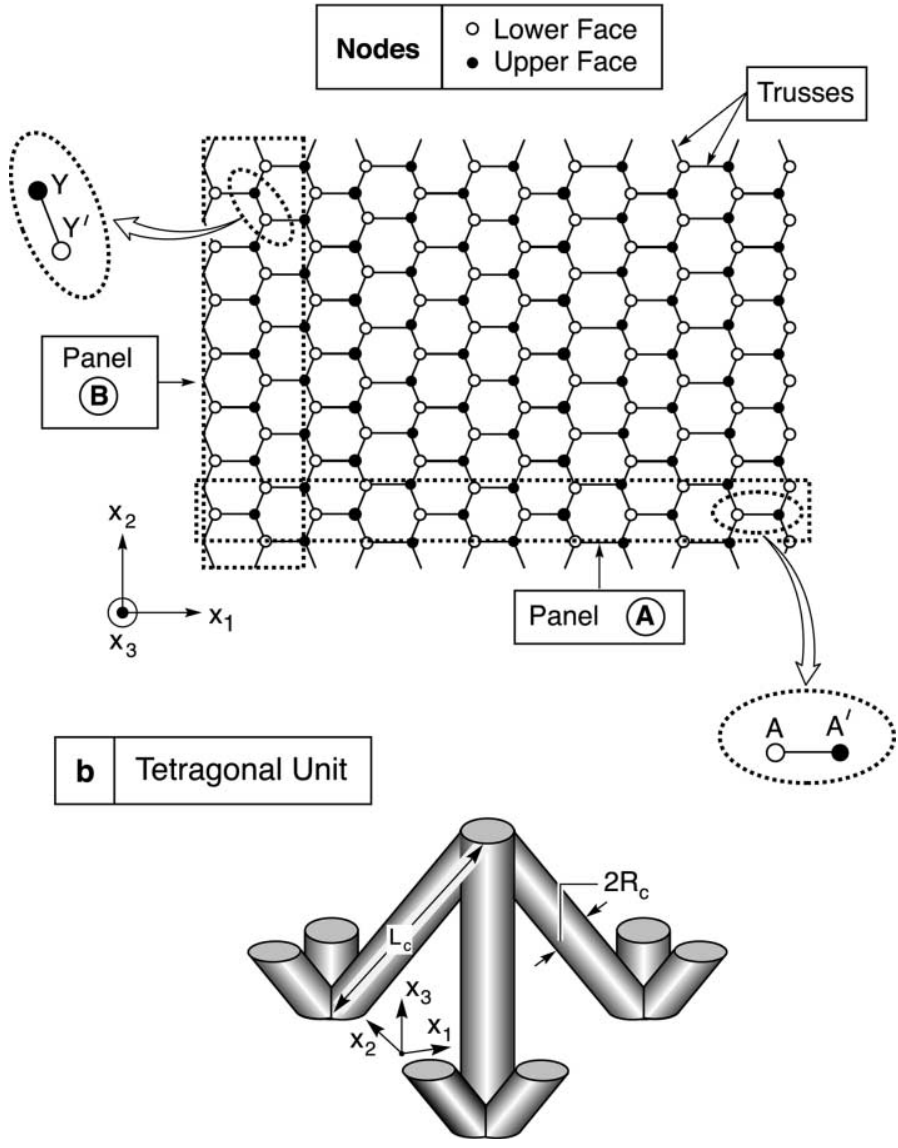

Fig. 1. (a) A plan view of the panel with the octet truss core showing the two basic orientations, A and B. In this study only orientation A has been tested; (b) A schematic of the tetrahedral unit characterizing the core, with the notation used in the analysis incorporated.

of type A and B (Fig. 1). Type A panels are emphasized in this study. When such panels undergo bending, the most highly stressed trusses (AA' in Fig. 1a) can experience either tension or compression, depending on the sign of the imposed shear force, $V$. This difference results in asymmetries, vividly demonstrated below. At the optimum, panels made from materials having high yield strain $\left(\varepsilon_{Y}=0.007\right)$, are predicted to fail by simultaneous elastic buckling of the compressed core members, with yielding and wrinkling of the faces (Wicks and Hutchinson, 2001). As $\varepsilon_{Y}$ decreases, the failure modes change to simultaneous core yielding with yielding and wrinkling of the faces. Theoretical results reveal that the optimized truss core design is capable of sustaining bending and compression loads at weights at least as low as the lightest competing designs (Wicks and Hutchinson, 2001; Ashby et al., 2000; Budiansky, 1999). The truss design has the additional merit that its open micro-architecture allows secondary functionality, such as cooling and actuation (Evans et al., 2001; Budiansky, 1999; Evans et al., 1998). When designed for minimum weight, the optimized panels (as well as honeycomb panel analogues) have relatively thin face sheets (Wicks and Hutchinson, 2001; Deshpande et al., 2001). This thinness causes them to be susceptible to face penetra- 
tion by sharp objects, and other related damage modes. Accordingly, designs with thicker faces are generally used (subject to a weight penalty), dictating that this study assesses panels with thicker than optimum faces.

The goal of the present study is to examine the capabilities of near-optimized panels, with the focus on core performance. The approach is to use measurements conducted on fabricated truss core panels to probe the mechanical performance and to correlate with the theoretical expectations. A previous study (Deshpande et al., 2001; Deshpande and Fleck, 2001) has provided several insights relevant to the design of the present samples. Namely, in the earlier work, under shear load in the negative orientation (Fig. 1b), susceptible to failure by compressive yielding of core members, while the measured load capacities were in accordance with the analytical results, there were discrepancies in the stiffness. Moreover, under shear load in the converse (positive) orientation, governed by yielding of the core members in tension, failure occurred prematurely by rupture of the nodes, rather than by yielding, resulting in a disparity with the predictions. This detrimental failure mode was attributed to the relatively low ductility of the cast aluminum alloy (Deshpande et al., 2001; Deshpande and Fleck, 2001), in combination with node eccentricity (Karlsson and Hyun, 2001). Accordingly, to realize the range of failure modes, the constituent material should have sufficient ductility to suppress premature rupture and the nodes must be designed to minimize eccentricity. These realizations guided the experimental study reported in the following sections.

In order to correlate with the measurements, new simulations of panel performance are conducted. These are based on the precise topology used in the experiments, as well as the measured stress/strain response of the new casting alloy. In the simulations, the full force/displacement responses of panels in bending and shear are predicted and these results are compared with the measurements.

\section{Experimental protocol}

The underlying concept is to devise bending, shear and compression tests on panels with optimal and sub-optimal core configurations that probe panel load capacity, stiffness and failure mechanisms. The configurations to be tested are designed with thicker than optimum face sheets as well as cores ranging in topology from optimal (Wicks and Hutchinson, 2001) to sub-optimal. A "gap" design was used for the nodes, wherein the intersection of the truss axes was located at the mid-plane of the optimized facesheet. To within $100 \mu \mathrm{m}$, this geometry was used in all of the fabrication and testing.

Ductility requirements are achieved by selecting a ductile beryllium-copper alloy, which exhibits a strain-to-failure in excess of $20 \%$ in the as-cast state. The panels were fabricated using a rapid prototyping and investment casting procedure elaborated in the next section. Four fabrication restrictions have enforced some limitations on the panel design. (i) It has not been possible to cast truss members either having an aspect ratio $\left(L_{\mathrm{c}} / R_{\mathrm{c}}\right)>28$ or faces having thickness, $t_{\mathrm{f}}<1.5 \mathrm{~mm}$. (ii) The largest panel that could be prototyped in the available system had a length, $L \leqslant 15 \mathrm{~cm}$. (iii) The final samples had dimensions that varied from design specifications by up to $7 \%$, despite rapid prototyping to account for an expected $1.8 \%$ shrinkage upon casting. (iv) Some warping of the panels during casting was unavoidable. Deviations from planarity are about $0.3 \mathrm{~mm}$ over the length, $L$.

The casting limitation on the truss radius, when considered in combination with the optimal truss aspect ratio for a chosen loading condition $\left(V / \sqrt{E M}=0.002,\left(L_{\mathrm{c}} / R_{\mathrm{c}}\right)_{\mathrm{opt}}=22.4\right)$ determined the core dimensions. The corresponding optimal face sheet was much thinner than casting procedures could produce. Furthermore, due to warping, the faces could not be ground to the optimal thickness. Accordingly, all of the tests were performed with panels having faces up to seven times thicker than the optimum, consistent with the dictates of commercial practice. For this purpose, panels were fabricated with constant face thickness, $t_{\mathrm{f}}=1.5 \mathrm{~mm}$, truss length, $L_{\mathrm{c}}=14.01 \mathrm{~mm}$ and core thickness, $H_{\mathrm{c}}=11.44 \mathrm{~mm}$, but three different truss radii: $R_{\mathrm{c}}=0.58,0.69,0.83 \mathrm{~mm}$. For these three radii, the relative core densities are, respectively (see Eq. (A.5)): 
$2.25 \%, 3.24 \%$ and $4.64 \%$. The smallest radius gave a truss aspect ratio closest to the optimum (Wicks and Hutchinson, 2001).

\section{Fabrication}

\subsection{Rapid prototyping}

Integrated face sheet and truss core sandwich panels were made by using rapid prototyping to fabricate acrylonitrile-butadiene-styrene (ABS) patterns, which were then used for investment casting from a high thermal conductivity beryllium-copper casting alloy $(\mathrm{Cu}-2 \% \mathrm{Be})$. Rapid prototyping has gained wide interest in the design community since it provides a means of: (a) visualizing new product ideas and, (b) fabricating parts for functional testing. Since the basis is a computer generated three-dimensional solid model of the object, it provides the convenience of creating panels of optimal, near optimal and suboptimal designs for performance evaluation. A slicing algorithm defines tool paths for the outer boundaries of each layer and the areas in which material needs to be filled. This information is downloaded to a rapid prototyping machine to generate the part. In this work, an extrusion-based, fused deposition modeling (FDM) process commercialized by Stratasys Inc., Eden Prairie, Minnesota was used (Crump, 1992).

The FDM process chosen uses ABS in filamentary form as the modeling material. The material is fed into a temperature-controlled heater/liquifier through counter-rotating rollers, and is then extruded through a fine nozzle in a semi-liquid state (Fig. 2). A second liquifier and nozzle system is used to extrude an easily

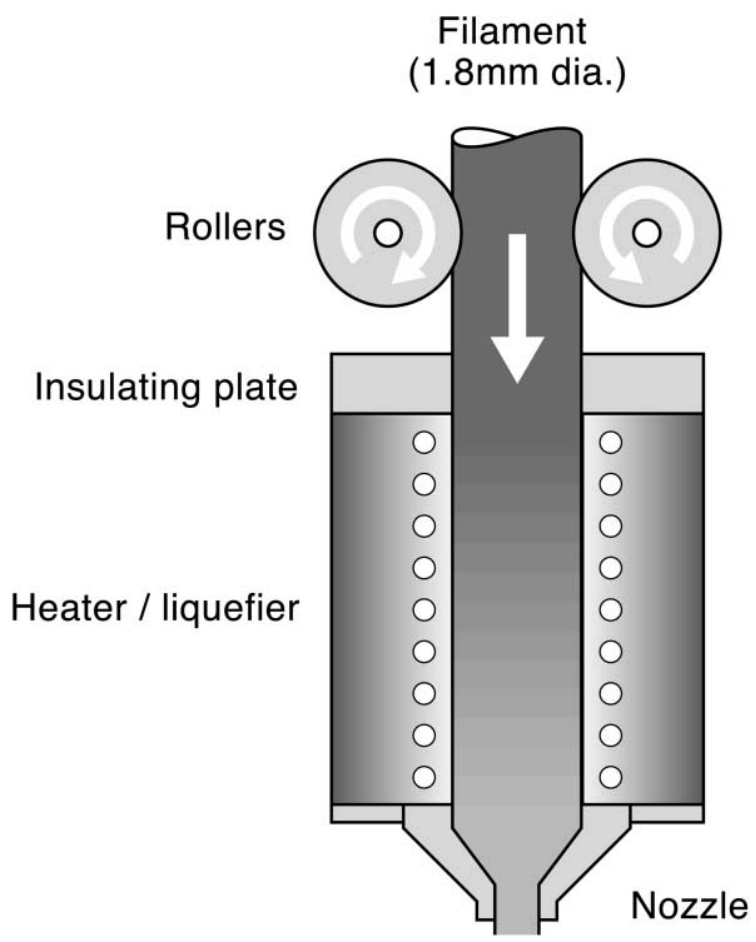

Fig. 2. Schematic of the fused deposition modeling process. 
dissolved material for a support structure, which can be removed upon build completion. Prior to applying the slicing algorithm, the part is rotated to the orientation that minimizes the support structure. The feeding system is contained in a head whose movement is numerically controlled in the $X-Y$ horizontal plane. A constraint on the overall panel dimensions was imposed based on the space available in the rapid prototyping machine.

The CAD model was built as an assembly of two face sheets and a truss core design. The panel length was selected to provide adequate overhang beyond the spacing of the outer load supports $(2 \mathrm{l}=148.8 \mathrm{~mm})$ and the panel width to accommodate four cells (Fig. 1). For beryllium-copper, a shrinkage allowance of $1.8 \%$ was added to the final pattern dimensions. After rapid prototyping, the parts were placed in a soluble concentrate and water solution at $70^{\circ} \mathrm{C}$ to dissolve the support structure. After the parts were sufficiently dry, a coat of clear acrylic spray was applied to fill-in gaps between the individual layers of the model.

\subsection{Investment casting}

The ABS patterns were coated with a liquid wax and cleaned with isopropyl alcohol. Seven wax gates were placed in a staggered arrangement to ensure a quick molten metal feed into the two face sheets (Fig. 3). Casting wax runners were then placed connecting the seven gates. Three vent channels were provided at the center and two ends of the sandwich panel to allow gases to escape from the mold during ABS burn-out (Fig. 4). The gated patterns were dipped in a ceramic slurry containing colloidal silica (supplier, Ransom and $\mathrm{Randolph})$, and zircon $\left(\mathrm{ZrSiO}_{4}\right)$. After allowing the slurry to drain, the patterns were then coated with a fine-grained zircon. The shells were allowed to air dry at approximately $23{ }^{\circ} \mathrm{C}$ for about a day and a half. A second dip was done in a slurry containing colloidal silica (Nyacol) and zircon. After draining the excess slurry the patterns were again coated with zircon and allowed to dry. The procedure was repeated for two more layers of the second slurry mix (third and fourth overall layers) and medium grain fused silica. The last three layers (5-7) used the second slurry mix followed by a coarse grained fused silica in order to add strength to the shell. After the seventh layer had dried, the patterns were dipped one last time (referred to as

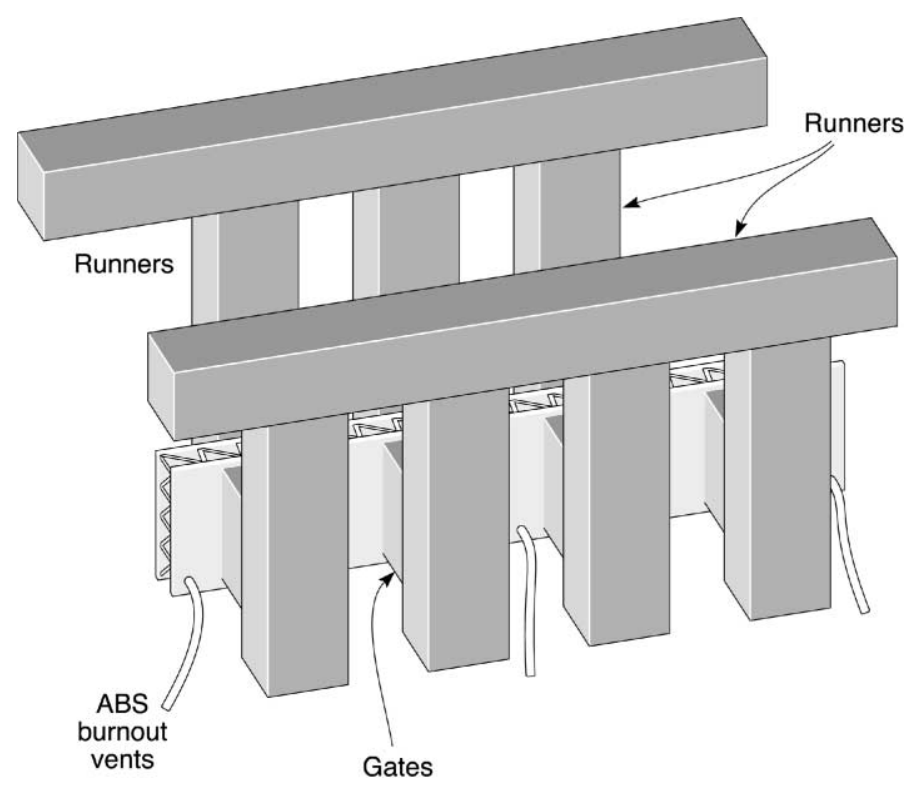

Fig. 3. Attachment of wax runners and burn out vents prior to ceramic shelling process. 


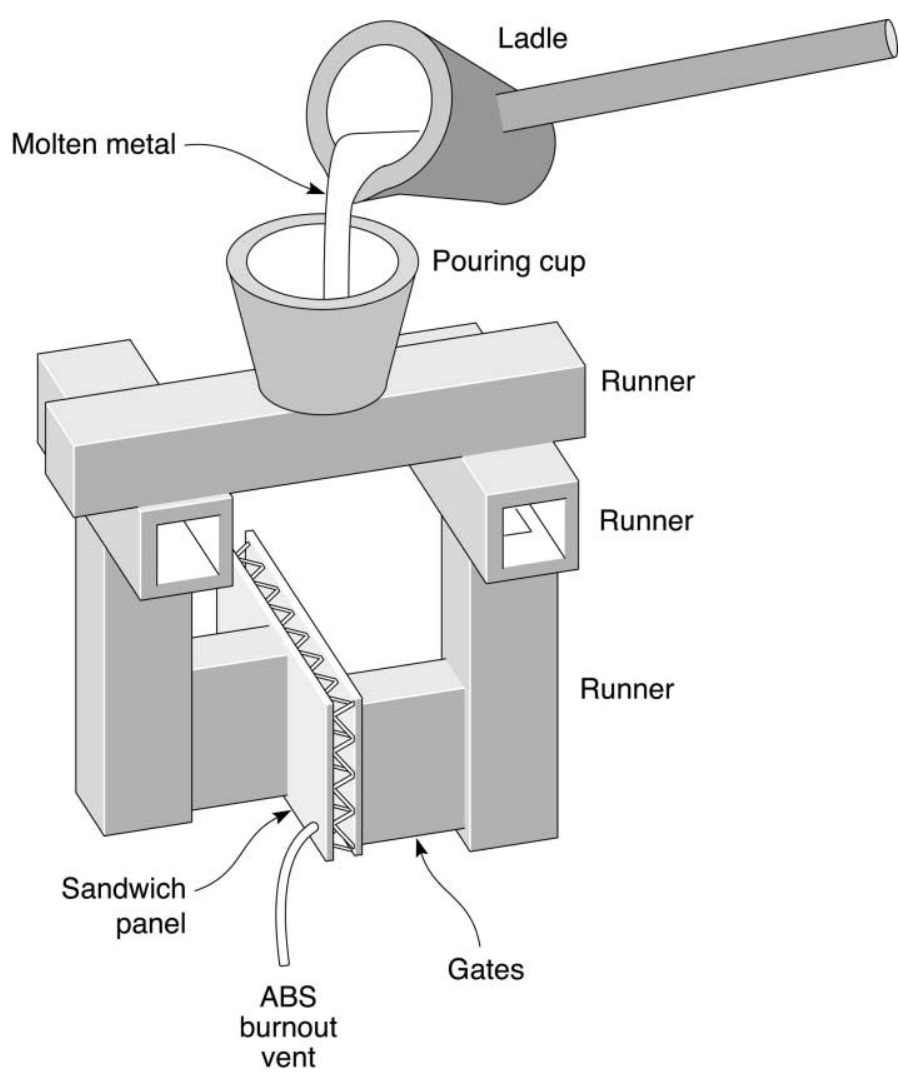

Fig. 4. Molten metal is poured into the ceramic shell after the ABS burnout process.

the "seal" coat) in the second slurry mix to prevent the sand from the previous coats from falling off the shell and getting inside the cavity at the burnout stage. After the seal coat was dry, the tips of the vents were ground to allow gases to escape during the ABS burnout process.

The ceramic shelled ABS panels were preheated to $900{ }^{\circ} \mathrm{C}$, placed in a furnace, the temperature ramped up to $1066{ }^{\circ} \mathrm{C}$ and held for $1.5 \mathrm{~h}$. The hollow shell molds were removed and allowed to cool to room temperature for inspection of cracks. Residual ash in the shells was removed by rinsing with water and a high-pressure air jet. The vents were plugged with a refractory cement and the shells placed back in the furnace and heated to $\sim 980{ }^{\circ} \mathrm{C}$. The alloy was induction melted in a $14 \mathrm{~kg}$ crucible and poured in to the mold at $1425{ }^{\circ} \mathrm{C}$.

When the shells had cooled after casting, the shell material was removed using a high-pressure water jet. The runner system was cut-off at the gates and ground flush with the surface of the face sheets using a twostage grinding operation.

\subsection{Microstructure and defects}

After fabrication and before testing, metallurgical sections were made at various locations in the panels. A random section (Fig. 5) shows the dendritic structure expected for this alloy. Sections made through several of the nodes (Fig. 6) revealed casting porosity. 


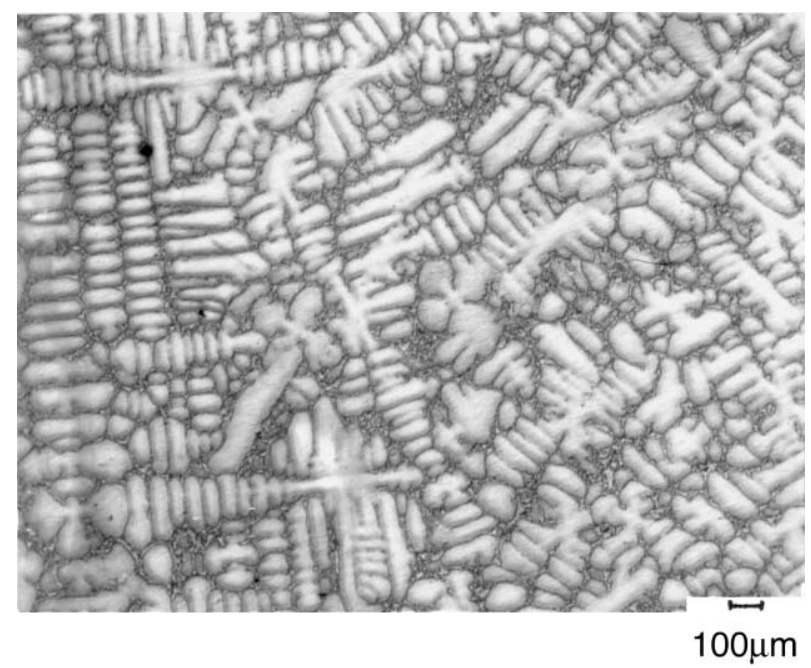

Fig. 5. As-cast microstructure of $\mathrm{Cu}-2 \% \mathrm{Be}$.
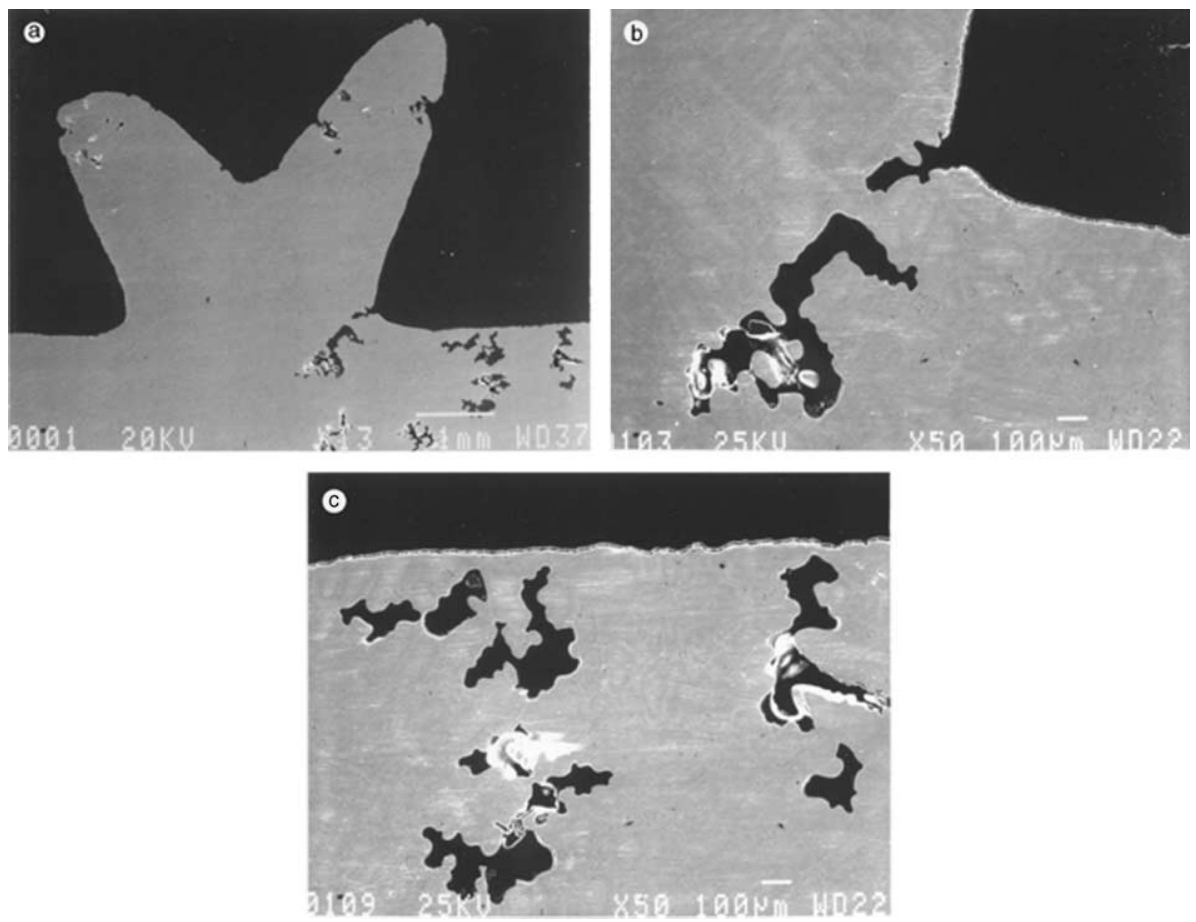

Fig. 6. (a) Cross-section through face sheet and a node; (b) Defects at node-face sheet intersection; (c) Casting porosity in face sheet. 


\section{Test design}

\subsection{Constituent properties}

The basic stress/strain behavior for the $\mathrm{Cu} / \mathrm{Be}$ alloy has been measured in the following manner. A face sheet from one of the cast panels was cut away from the core and a flat coupon tensile specimen prepared. The reduced gage section had dimensions, $6 \times 2 \times 45 \mathrm{~mm}$. The specimen was tested in a servo-hydraulic machine by using friction grips, with strain gages centered on both sides of the mid-section. The stress/ strain curve obtained on the as-cast material is plotted in Fig. 7. In this condition, the material has a tensile ductility exceeding $20 \%$. It has a $0.2 \%$ offset yield strength of $300 \mathrm{MPa}$. The unload/reload lines confirm a Young's modulus, $E=130 \mathrm{GPa}$. The considerable strain hardening can be captured using the RambergOsgood formulation:

$$
\varepsilon=\sigma / E+\alpha \varepsilon_{\mathrm{Y}}\left(\sigma / \sigma_{\mathrm{Y}}\right)^{N} .
$$

The measurements afford an excellent fit to (4.1), as evident from Fig. 7, with: $\alpha \approx 1, N=7.4, \sigma_{\mathrm{Y}}=291$ $\mathrm{MPa}$, and $\varepsilon_{\mathrm{Y}}=2.23 \times 10^{-3}$.

\subsection{Three-point bending}

The panels were tested in three-point bending by using a procedure similar to that described elsewhere (Bart-Smith et al., 2001), and as depicted in Fig. 8. Flat-faced loading platens $16 \mathrm{~mm}$ wide were adhesively bonded to the faces of the panels. The loads were applied through lubricated rollers inset into the platens that allowed the specimen to rotate upon bending, with minimal friction. Strain gages were bonded to the tensile face at two locations. One set was attached to the face immediately opposite the inner platen. Strains were monitored in both $0^{\circ}$ and $90^{\circ}$ orientations. A second set was attached to the same face mid-way between the center and outer platens. The tests were performed in a servo-electric test frame. The load, load-point displacements and strains were measured simultaneously.

An assessment of the expected failure mechanisms for each of the panels described in Section 2 provides perspective prior to testing. By inserting the properties of the as-cast alloy (Fig. 7) into the beam theory formulae in Appendix A, the limit load, $P_{\max }$, needed to cause failure by core and face yielding can be

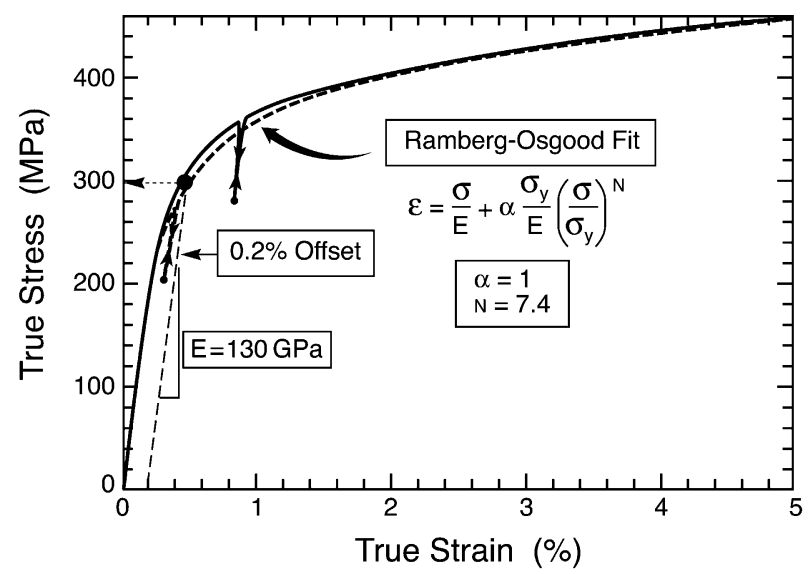

Fig. 7. The tensile stress/strain response of the as-cast material, showing the Ramberg-Osgood fit. The unload/reload lines indicate a Young's modulus, $E=130 \mathrm{GPa}$. 

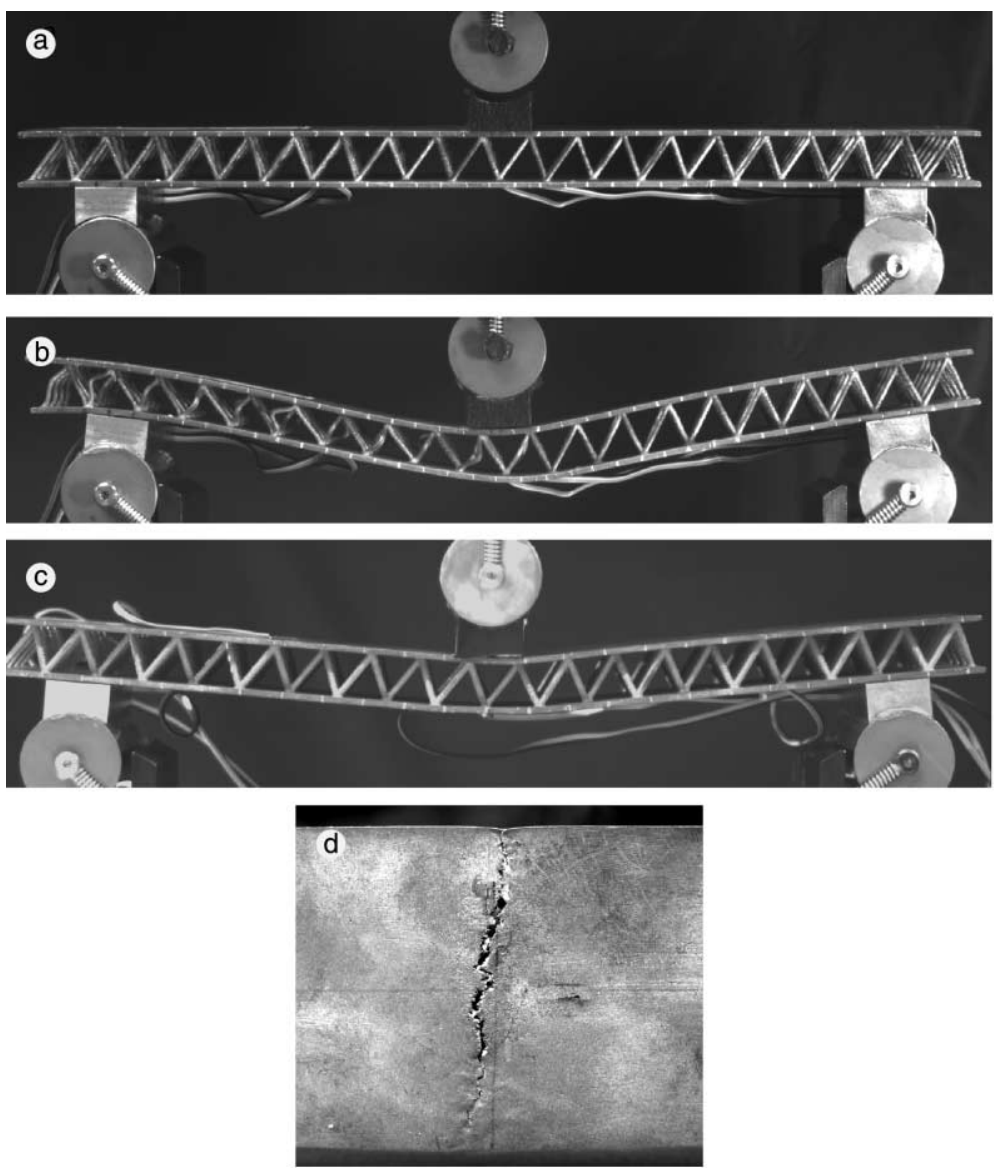

Fig. 8. (a) Optical image of the side of one of the panels, truss core radius, $R_{1}=0.58 \mathrm{~mm}$ located in the bending fixture, showing the loading scheme; (b) Image of the same panel after testing showing the asymmetry of the displacements that occur upon testing. Plastic hinges are apparent at the inner platen as well as at the outer platen on the side that experiences large core shear strains (but not on the other side); (c) Image of a panel with larger trusses, $R_{1}=0.82 \mathrm{~mm}$ that fails by face yielding; (d) Note the tear that has extended along the width at the center-line of the face in tension.

estimated for each configuration, as plotted in Fig. 9. (Face wrinkling is another possible mechanism (Wicks and Hutchinson, 2001; Gibson and Ashby, 1997). But, at the face thickness achievable in the fabricated panels, it always occurs at a much higher force than the two yielding mechanisms). Note that panels with all three core radii are predicted to fail by core yielding, although the largest approaches the transition from core yield to face yield.

\subsection{Shear and compression tests}

The configuration used to obtain shear stress/strain curves for the core is shown in Fig. 10. Three guidelines were used in the design. (i) The avoidance of significant tensile stress normal to the core to prevent premature rupture of the nodes. (ii) Minimization of the normal stresses induced near the ends. (iii) Sufficient rigidity to minimize rotation of the nodes at the face sheet. The resultant design comprised a static frame rigidly attached to a thick base and a moving element with the freedom to displace vertically but not 


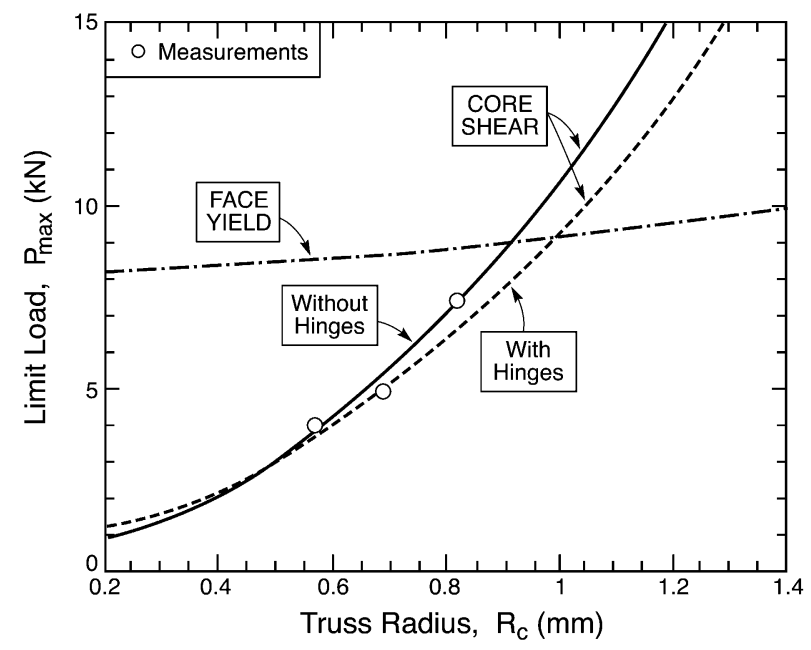

Fig. 9. The limit loads predicted as a function of the truss radius for failure by face yielding, and core shear both with and without the presence of plastic hinges at the outer load platens. The measured values are also shown for comparison. For the calculations, the core yield strength was taken to be the average value of the plastic buckling stress calculated using (A.8) for the three geometries tested. The face sheet yield strength has been represented by the Ramberg-Osgood fit.

horizontally. The parts interact through two $6 \mathrm{~cm}$ linear bearings (circulating ball guide blocks and rails) that assure rigid linear motion with minimal friction. The test specimen was rigidly attached to the sliding component by means of holes tapped into the face. In some cases, a steel spacer was used to assure that the loads were aligned with the center of the sample. The load was applied in a servo-electric test frame.

Since transverse displacements are induced during shear, as elaborated in Section 6, a means for accommodation that minimizes the induced stresses was incorporated. This was achieved by embedding an array of pins into the face of the static frame. These were inserted into matching holes in the panel face. The lateral movement occurred by displacement of the holes in the plate relative to the pins. Frictional effects were reduced by polishing and lubricating the contact surfaces. Samples were designed to minimize the development of a moment by arranging a single row of nodes on the face sheet displacing through the pins.

In order to explore the crushing characteristics, compression tests were conducted in the orientation normal to the panel faces by simply compressing a reduced panel $(4 \times 4 \mathrm{~cm})$ between large flat platens within a servo-electric test frame.

\subsection{Observations}

During the bending and shear tests, a high-resolution digital camera was connected to the test frame in order to capture side-view images of the core, while the tests were being conducted. These images were used to identify the failure mechanisms and to determine the shear strains.

\section{Measurements}

\subsection{Panel bending}

The load/displacement curves measured in bending are summarized in Fig. 11a. A peak load, $P_{\max }$ is attained, at displacement, $\delta_{\max }$, followed by softening. The panels with the two smaller truss radii fail by 


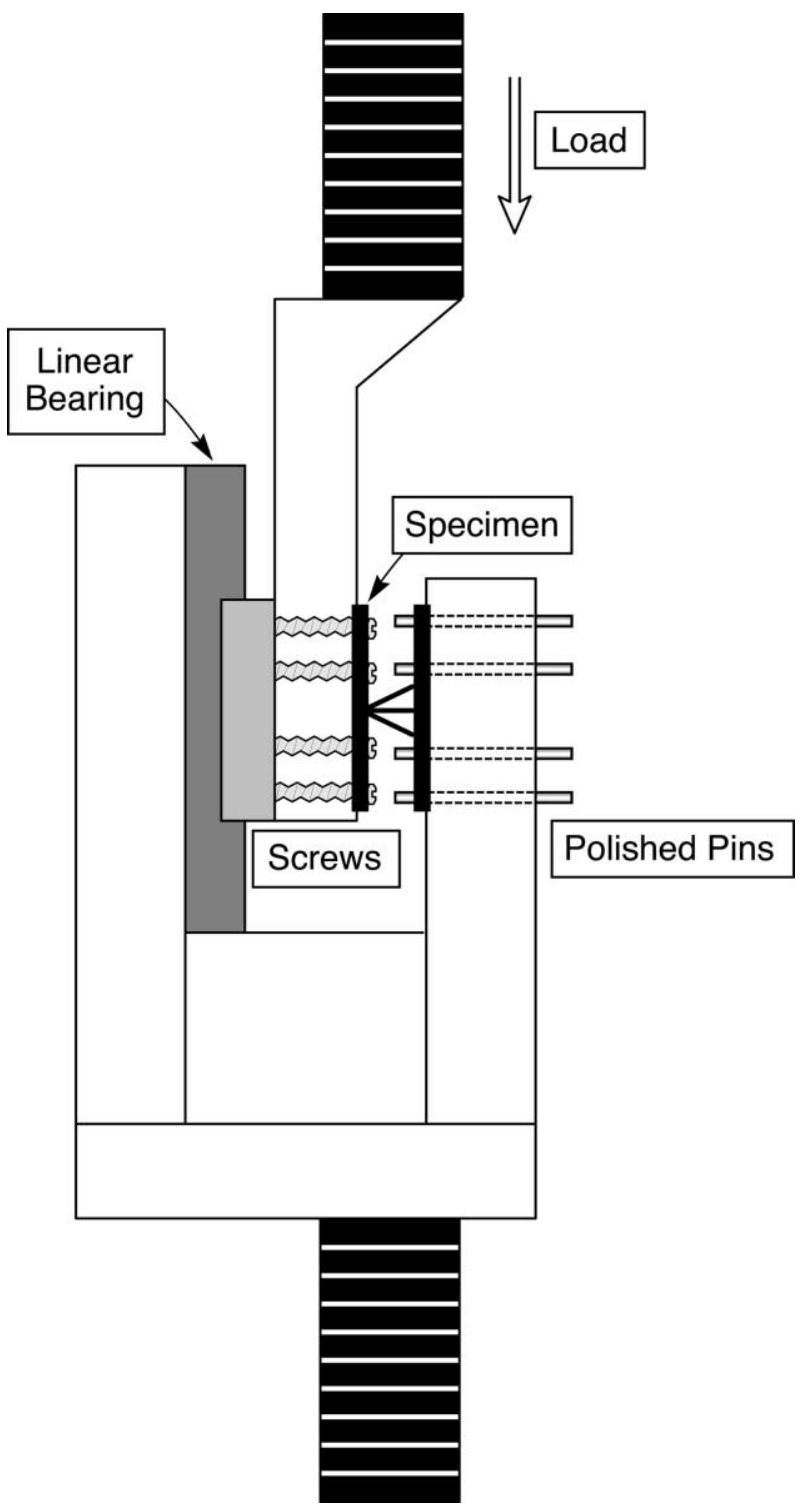

Fig. 10. The configuration used to determine the shear stress/strain response for the truss cores.

core shear (see Fig. 8a and b) and the softening is gradual. The panel with the largest truss radius fails by face yielding (see Fig. 8c and d) and the softening occurs rapidly. All panels experience inelastic strain at small loads (see unload/reload lines in Fig. 11b), with strong strain hardening prior to the load maximum.

The measured variation in $P_{\max }$ with the truss radius is indicated in Fig. 9. The bending stiffness, $S_{\mathrm{B}}$ is ascertained from the unloading compliance determined at displacements $\leqslant \delta_{\max }$, and plotted in Fig. 12. The "initial loading stiffness", $S_{\text {Initial }}$ denoted in Fig. $11 \mathrm{~b}$, is about a factor 2 lower than $S_{\mathrm{B}}$. A similar disparity arises in metal foams and foam core panels, because of local yielding at nodal stress concentrations (Ashby et al., 2000). 

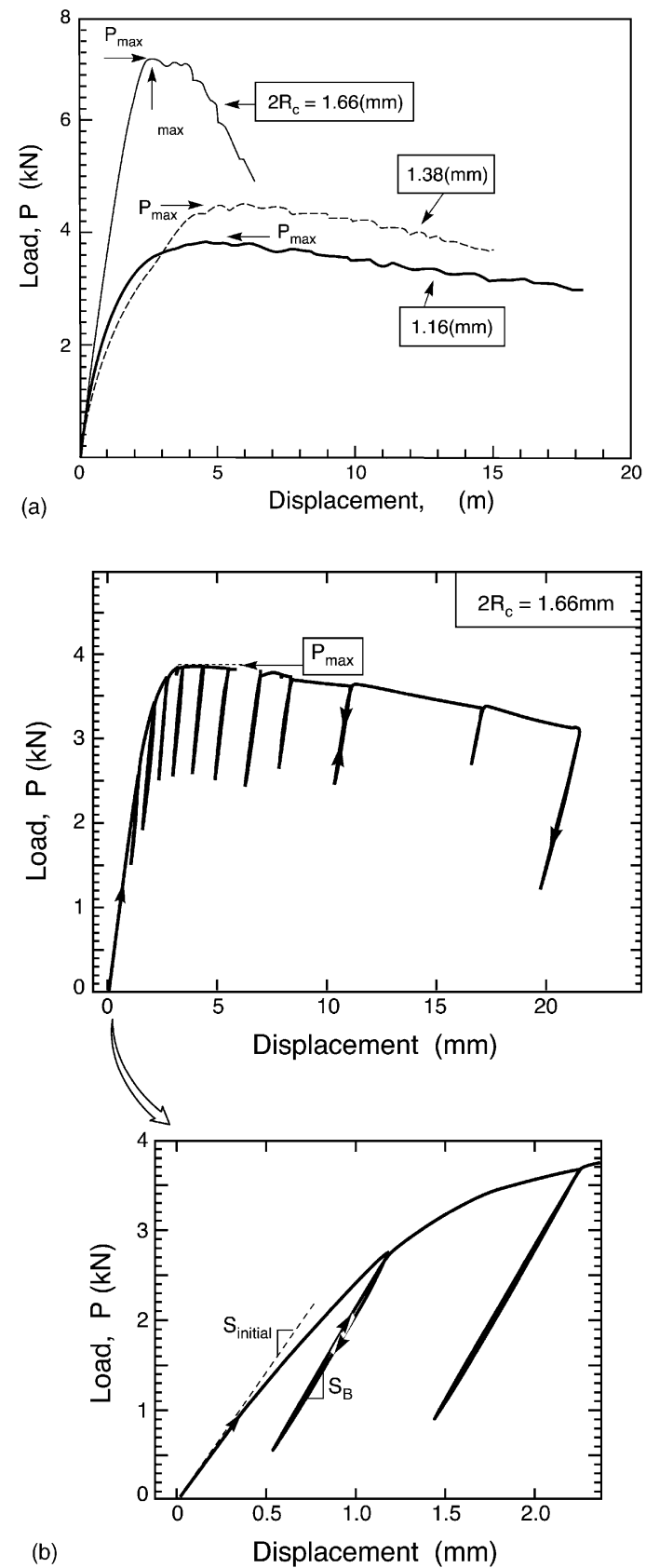

Fig. 11. (a) The load/deflection responses measured on the panels with the three truss radii; (b) The result for the panel having the smallest truss core radius highlighting the existence of a load maximum, followed by softening, as well as the difference between the unloading stiffness and the initial loading stiffness.

Images of the test performed on the panel with the smallest truss radius (Fig. 8a and b) indicate that it fails by core shear and that the response beyond the load maximum is asymmetric. This happens because 


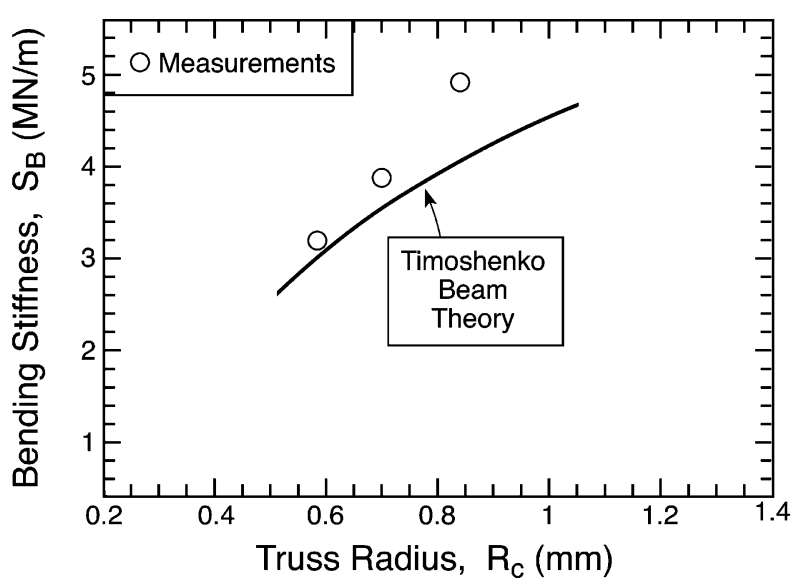

Fig. 12. The effects of truss radius on the bending stiffness. Results expected from beam theory are shown for comparison, as elaborated in the text.

the trusses that experience the largest stresses are in compression on one side and in tension on the other. On the compression side, the trusses buckle plastically, resulting in large inelastic shear strains, causing plastic hinges at both the center and outer load platens. On the tensile side, the trusses stretch and sustain the load at essentially fixed strain, whereupon the panel remains straight at the outer platen.

The corresponding images obtained on the panels with larger truss radii that fail by face yielding (Fig. 8c and d) indicate that the plastic deformation is confined to the face sheet subject to tension. This face begins to neck and tear along the center-line at the load maximum (Fig. 8d). The tear extends across the sheet as the displacement increases, but the core continues to support some shear stress, thereby inhibiting abrupt rupture of the panel.

The output of the strain gages for the test on the panel with the smallest radius (depicted in Fig. 11a) is presented in Fig. 13a. The plot of stress vs. axial strain measured beneath the center platen has a shape similar to that of stress against load point displacement. The unload/reload lines indicate that some face sheet yielding commences at quite small loads (about $2 \mathrm{kN}$ ) and that, at the load maximum, the plastic strains in the faces are about $0.1 \%$. The transverse strains at the center are consistent with a Poisson contraction of the face: with a Poisson ratio in the elastic range, $v \approx 0.25$. At the quarter-span location, the strain in the elastic range is half that at the center, as expected from beam theory. However, once the core has yielded (causing the face-sheet beneath the center load platen to become plastic), the face at the midspan begins to unload, resulting in a compressive residual stress (apparent from extrapolation of the unloading lines). Note that the mid-span gage is on the side of the central platen where the trusses buckle plastically, discussed next.

The center $0^{\circ}$ strain measured on one of the specimens that failed by face yielding is indicated in Fig. 13b. The response up to the maximum load is similar to that for the other panel. At that stage, the central strain gage begins to unload as the tear in the face diminishes the retained load capacity. This occurs at a strain, $\varepsilon_{x} \approx 0.67 \%$.

\subsection{Panel shear}

The stress/strain responses measured in shear on specimens having the largest aspect ratio trusses are plotted in Fig. 14a. The strains were obtained from the optical images. They establish that the shear load 

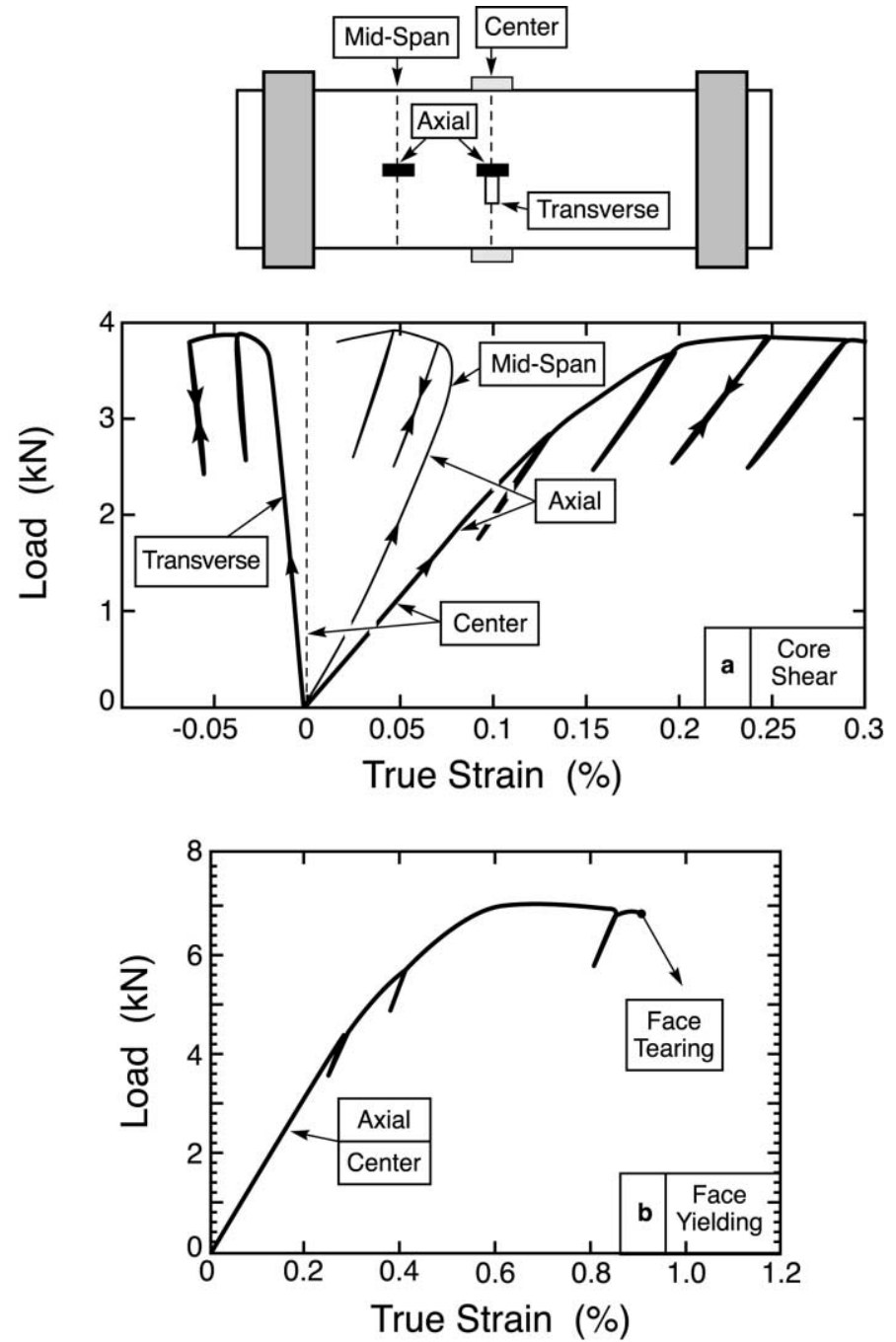

Fig. 13. The face layer strains as a function of bending load; (a) The panel having the smallest truss radius that fails by plastic buckling of the core. The mid-span gage is located on the side that experiences plastic buckling; (b) The panel with the largest truss that fails by face yielding.

capacity differs appreciably in the two orientations. That is, the limit load is lower in the negative orientation (defined in the inset) wherein the most heavily stressed trusses are in compression, in contrast to the positive orientation that places the equivalent trusses in tension.

The optical images indicate that, in the negative orientation, plastic buckling occurs at shear strains of about $2.35 \%$ (Fig. 15b). Conversely, in the positive orientation, the most highly stressed trusses stretch plastically and transfer load onto the compressed trusses. Due to a slight curvature of one of the truss members, plastic buckling occurred prematurely, at about $2.0 \%$ strain. Nevertheless, the truss under tension partially compensated for the buckling, allowing the sample to continue hardening. After testing it was noted that some of the trusses (about 10\%) had ruptured at the nodes, presumably at locations where there is appreciable casting porosity (Fig. 6). 


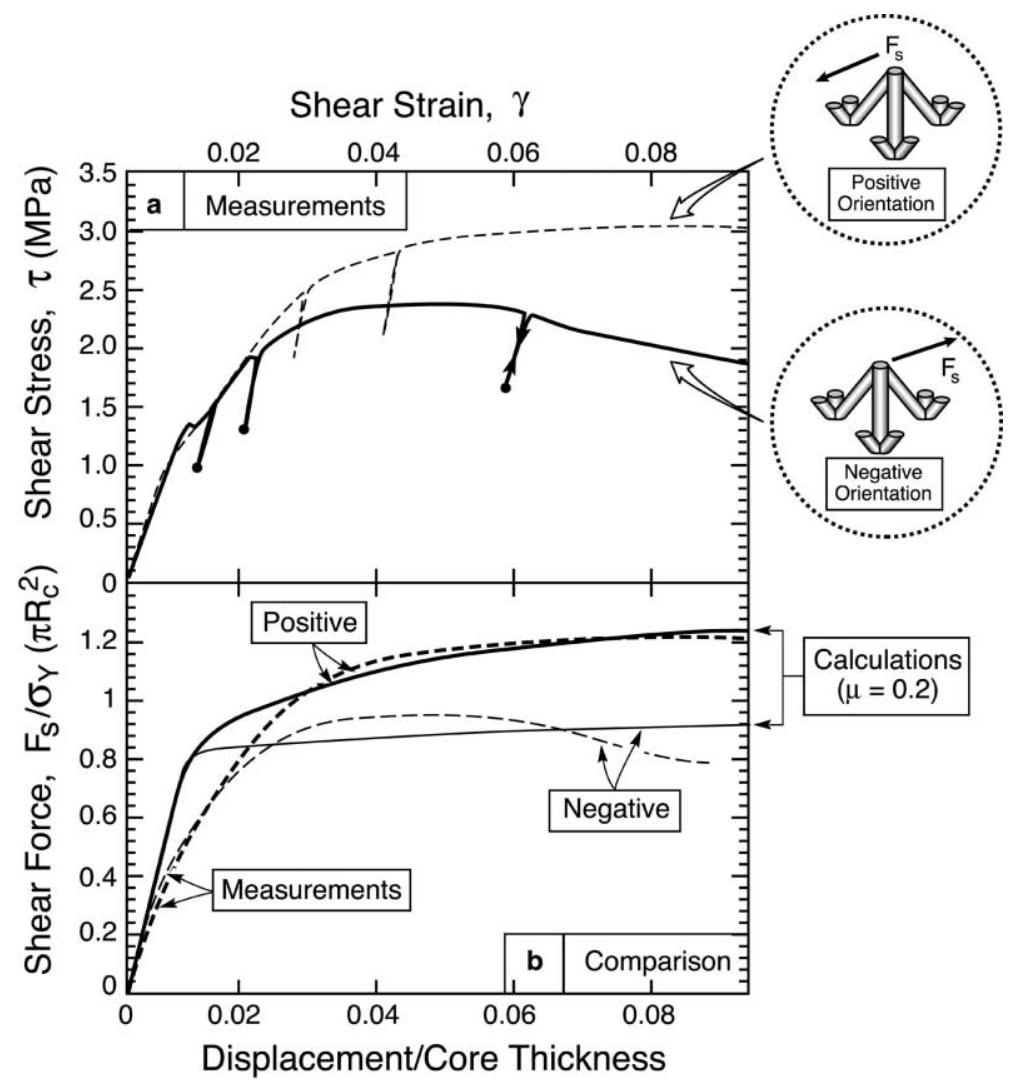

Fig. 14. (a) The shear stress/strain curves for the panels measured in the two principal orientations indicated on the insets conducted on panels having the smallest truss radius. Note the substantially larger limit load obtained for the positive orientation defined on the inset (most highly stressed trusses in tension). The strains were determined from the optical images; (b) The corresponding dependence of the shear force on the displacement relative to the core thickness, with the results calculated numerically superposed.

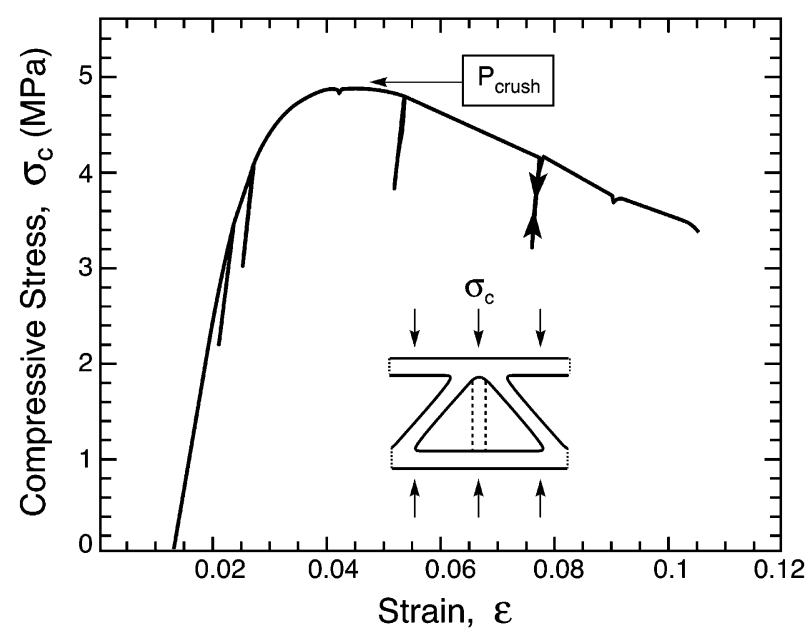

Fig. 15. The stress/strain response of the core measured in compression. 


\subsection{Crushing}

A simple compression test has been performed to measure the crushing characteristics of the core with the smallest diameter trusses. The result is plotted in Fig. 15. Note that the core sustains a peak stress, $P_{\text {crush }}=4.8 \mathrm{MPa}$ and then gradually softens. The optical images reveal that the trusses exhibit plastic buckling at the load maximum.

\section{Simulations}

Two simulations have been carried out to provide a direct comparison with the tests: (1) the isolated triad loaded by a shear force, and (2) the plate with the truss core loaded in three-point bending. In the plate simulation, a Timoshenko-type theory is developed in which the shearing behavior computed for the triad is used to specify the core stress/strain behavior. Details of the simulations are described below.

\subsection{Shear loading of an isolated triad}

The triad unit of the octet truss core is depicted in Fig. 1b, along with the two directions of shear force, $F_{\mathrm{s}}$. The test fixture is expected to exert some force perpendicular to the direction of the shear force due to frictional sliding. This component is modeled by $F_{\mathrm{n}}=\mu F_{\mathrm{s}}$ where $\mu$ is the coefficient of friction, and the sense of $F_{\mathrm{n}}$ is opposite to the direction of sliding. The joints are modeled as pinned such that bending of the members is ignored in computing the relation between $F_{\mathrm{s}}$ and $u$, the parallel displacement of the top face sheet relative to the bottom face sheet. This approximation is standard in truss analysis and fully justified because the stretching forces parallel to the members completely dominate the forces generated by bending prior to buckling. The two equations of equilibrium in the current configuration are:

$$
\begin{aligned}
& 2 F_{\mathrm{A}} \vec{t}_{\mathrm{A}} \vec{i}_{x}-F_{\mathrm{B}} \vec{t}_{\mathrm{B}} \vec{i}_{x}=F_{\mathrm{s}}, \\
& 2 F_{\mathrm{A}} \vec{t}_{\mathrm{A}} \vec{i}_{y}+F_{\mathrm{B}} \vec{t}_{\mathrm{B}} \vec{i}_{y}= \pm \mu F_{\mathrm{s}},
\end{aligned}
$$

where $F_{\mathrm{B}}$ is the force in the member under highest stress, $F_{\mathrm{A}}$ is the force in each of the other members in the triad and the sign of the friction force is consistent with the sliding direction. The strains in the members are computed from the change in length and the two displacement components, $u$ and $v$ (the horizontal and vertical displacements respectively of the top joint relative to the bottom face of the fixture). The stress in a member, $\sigma=F /\left(\pi R_{\mathrm{c}}^{2}\right)$, is related to the strain by (4.1).

Member $\mathrm{Y}$ is compressed for loading in the negative orientation, and will buckle when $F_{\mathrm{B}}$ attains the plastic buckling load. This member is taken to be clamped at each end such that the critical stress at the onset of plastic buckling is given by, $\sigma_{\text {crit }}=-\pi^{2} E_{\mathrm{t}}(R / L)^{2}$, where $E_{\mathrm{t}}$ is the tangent modulus of the stress/ strain curve (4.1). A post-buckling analysis has not been carried out. For plate simulation, the shear force, $F_{\mathrm{s}}$, is taken to be constant after buckling, ignoring the post-buckling fall-off. Plots of the normalized shear force calculated as a function of the overall shear strain, $\gamma=u / H_{\mathrm{c}}$, are shown in Fig. 16 for a frictionless loading fixture and for $\mu=0.2$. The asymmetry associated with loading in the positive and negative orientations is apparent. The influence of friction is relatively small. These calculated results have been superposed on the measurements in Fig. 14b. The comparison will be discussed below.

\subsection{Three-point bending of a sandwich plate with the octet truss core}

To appropriately simulate the load/deflection response in bending, note that the contribution of the shear stiffness of the core must be taken into account in predicting elastic deflections. Moreover, once the 


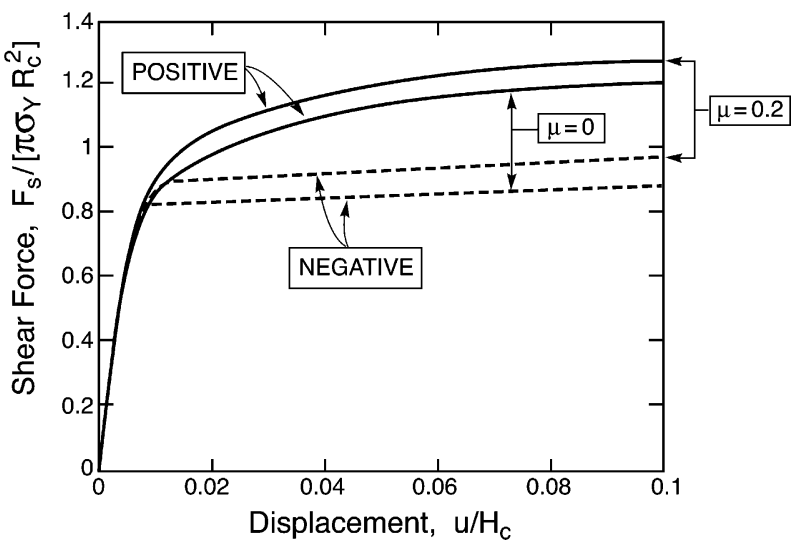

Fig. 16. The shear force/deflection response calculated for the core showing the asymmetry (refer to Fig. 14) and the effect of a friction coefficient $(\mu)$ operating at the loading fixture.

core yields, the non-linearity of the load/deflection response becomes compounded by the asymmetry attributable to plastic buckling of core members on the right side of the beam. A Timoshenko-type plate theory that fully accounts for these aspects of core shear is introduced. The model is restricted to loads wherein the face sheets remain elastic. Conventions related to the theory are shown in Fig. 17. The displacement components of the center-line are denoted by $[u(x), w(x)]$, and the core shear relating the displacement of the top face sheet $(+)$ relative to the lower sheet $(-)$ is $\gamma(x)$. The stretching strains in the top and bottom sheets are

$$
\varepsilon_{+}=u^{\prime}+\omega^{\prime} H_{\mathrm{c}} / 2, \quad \varepsilon_{-}=u^{\prime}-\omega^{\prime} H_{\mathrm{c}} / 2,
$$

where $\omega=\gamma-w^{\prime}$ and ()$^{\prime}=\mathrm{d}() / \mathrm{d} x$. The average stresses in the elastic face sheets are, $\sigma_{+}=\bar{E} \varepsilon_{+}$and $\sigma_{-}=\bar{E} \varepsilon_{-}$, with $\bar{E}=E /\left(1-v^{2}\right)$. The bending moments carried by the individual sheets are $M_{+}=M_{-}=$ $\left(\bar{E} t_{\mathrm{f}}^{3} / 12\right) w^{\prime \prime}$. The contribution from the truss core to the net in-plane force per unit length, $N$, is
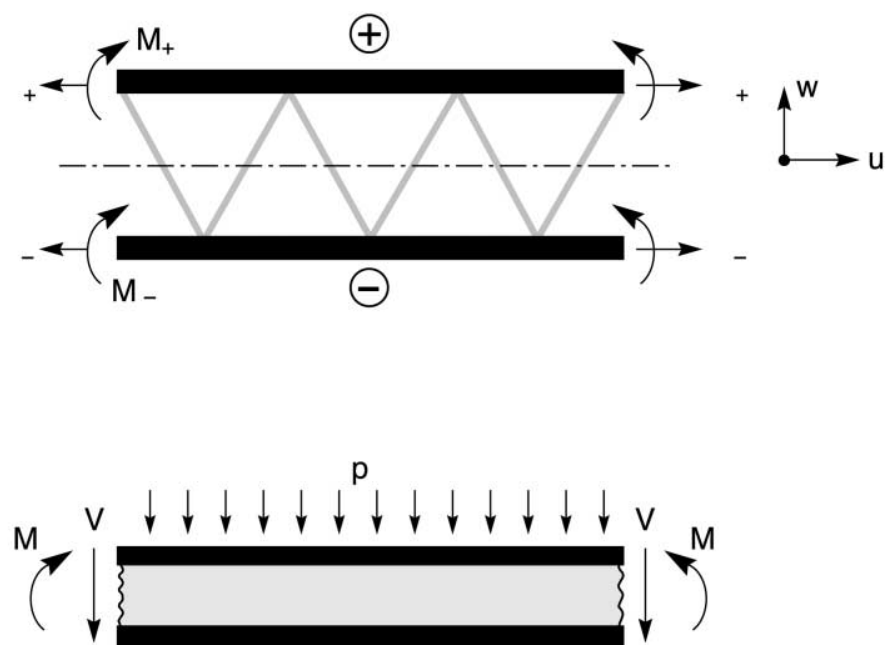

Fig. 17. The stresses and bending moments used for the analysis of the load/deflection response of the panel in bending. 
neglected: whereupon, $N=\sigma_{+} t_{\mathrm{f}}+\sigma_{-} t_{\mathrm{f}} \equiv 0$ and thus: $\sigma_{+}=-\sigma_{-} \equiv \sigma$. It follows immediately from (6.2) that $u^{\prime}=0$.

The net moment carried by the plate (again neglecting the very small contribution of the core) is:

$$
M=M_{+}+M_{-}-\sigma H_{\mathrm{c}} t_{\mathrm{f}}=\left(\bar{E} t_{\mathrm{f}}^{3} / 6\right) w^{\prime \prime}-\bar{E} t_{\mathrm{f}} H_{\mathrm{c}}^{2} \omega^{\prime} / 2 .
$$

Denote the non-linear shear stress/strain behavior of the truss core by $S(\gamma)$, taken directly from the force-displacement relation of the triad, $F_{\mathrm{s}}(\gamma)$, in Fig. 16 by dividing the force by the area of the unit triad cell, $S=F_{\mathrm{s}} /\left(\sqrt{3} L_{\mathrm{c}}^{2} / 2\right)$. Equilibrium of the face sheets requires:

$$
t_{\mathrm{f}} \sigma^{\prime}=S(\gamma)
$$

The overall equilibrium equations are the standard ones for any beam theory,

$$
V^{\prime}=p(x), \quad M^{\prime}=-V .
$$

The distributed lateral load per unit length vanishes: $p=0$. The three-point bend problem is statically determinate such that:

$$
\begin{aligned}
M \equiv M_{0}(x) & =0 & & -\ell-\Delta \ell<x<-\ell, \\
& =P \ell(1+x / \ell) / 2 & & -\ell<x<0, \\
& =P \ell(1-x / \ell) / 2 & & 0<x<\ell, \\
& =0 & & \ell<x<\ell+\Delta \ell,
\end{aligned}
$$

where the length of the overhang is denoted by $\Delta \ell$ and the loads are idealized as point forces applied at the center of the loading platens.

The two ordinary differential equations governing $\omega(x)$ and $w(x)$ (with $\gamma=\omega+w^{\prime}$ ) are thus:

$$
\begin{aligned}
& \frac{\bar{E} t_{\mathrm{f}}^{3}}{6} w^{\prime \prime}-\frac{\bar{E} H_{\mathrm{c}}^{2} t_{\mathrm{f}}}{2} \omega^{\prime}=M_{0}(x), \\
& \frac{\bar{E} H_{\mathrm{c}} t_{\mathrm{f}}}{2} \omega^{\prime \prime}=S\left(\omega+w^{\prime}\right) .
\end{aligned}
$$

Continuity across the points of application of the concentrated loads requires that all of $w, w^{\prime}, \omega$ and $\omega^{\prime}$ be continuous: the latter two ensuring that $\gamma$ and $\sigma$ are also continuous. The jump conditions at the concentrated loads are satisfied because the two equations in (6.7) are based on the statically determinate distribution. The boundary conditions are $w=0$ at $x= \pm \ell$ and $\omega^{\prime}=0$ at $x= \pm(\ell+\Delta \ell)$ : the second of these ensures that $\sigma=0$ at the free ends. The conditions that $M$ and $V$ vanish at the ends follow directly from (6.7). The equations in (6.7) can be put in non-dimensional form by letting $z=x / \ell,()=\mathrm{d}() / \mathrm{d} z$ and $\bar{w}=w / \ell$ such that:

$$
\begin{aligned}
& \bar{w}-3\left(H_{\mathrm{c}} / t_{\mathrm{f}}\right)^{2} \omega^{\prime}=6 \bar{M}_{0}(x), \\
& \omega^{\prime \prime}=2 \bar{S}(\omega+\bar{w}),
\end{aligned}
$$

where $\bar{M}_{0}=\ell M_{0} / \bar{E} t_{\mathrm{f}}^{3}$ and $\bar{S}=\ell^{2} S / \bar{E} t_{\mathrm{f}} H_{\mathrm{c}}$. A parameterized function, $\bar{S}(\gamma)$, was chosen to fit the computed curves for the triad in Fig. 16 (with $\bar{S}<0$ for $\gamma<0$, and $\bar{S}>0$ for $\gamma>0$ ). Because the computed prediction for the triad in Fig. 16 slightly underestimates the experimentally measured maximum load (Fig. 14), the value of $\bar{S}$ associated with onset of buckling in the present simulation was chosen consistent with $F_{\mathrm{s}} /\left(\pi R_{\mathrm{c}}^{2} \sigma_{\mathrm{Y}}\right)=1$, in better accord with the experimental value.

The system of equations (6.8) has been solved for the specific parameters associated with the three-point bend test in Fig. 8. This specimen has $R_{\mathrm{c}}=0.575 \mathrm{~mm}$, and the overhang was taken as $20 \mathrm{~mm}$. At each load $P$ the system (6.8) is solved using standard numerical techniques for ordinary differential equations with Newton iteration to deal with the non-linearity due to $\bar{S}(\gamma)$. 
The plot of load against maximum downward displacement is shown in Fig. 18. Prior to the onset of buckling in the core, the deflection of the beam is symmetric with respect to its center. However, once buckling starts on the right side of the beam, that side has less incremental stiffness and there is a tendency for slightly larger deflection than on the left, as has also been observed in the test (Fig. 8). The deflection in the overhang on the right is also affected because it resists shearing displacements at that end of the beam. The beam deflection shortly before and after the onset of buckling is shown in Fig. 19.

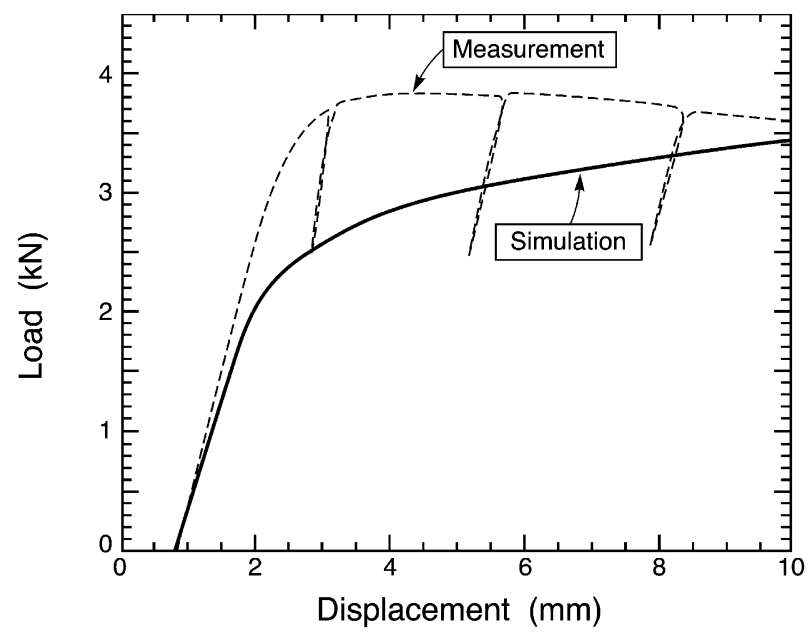

Fig. 18. The simulated load/deflection response in bending for the beam having the smallest truss diameter with the measured curve taken from Fig. 11a superposed.

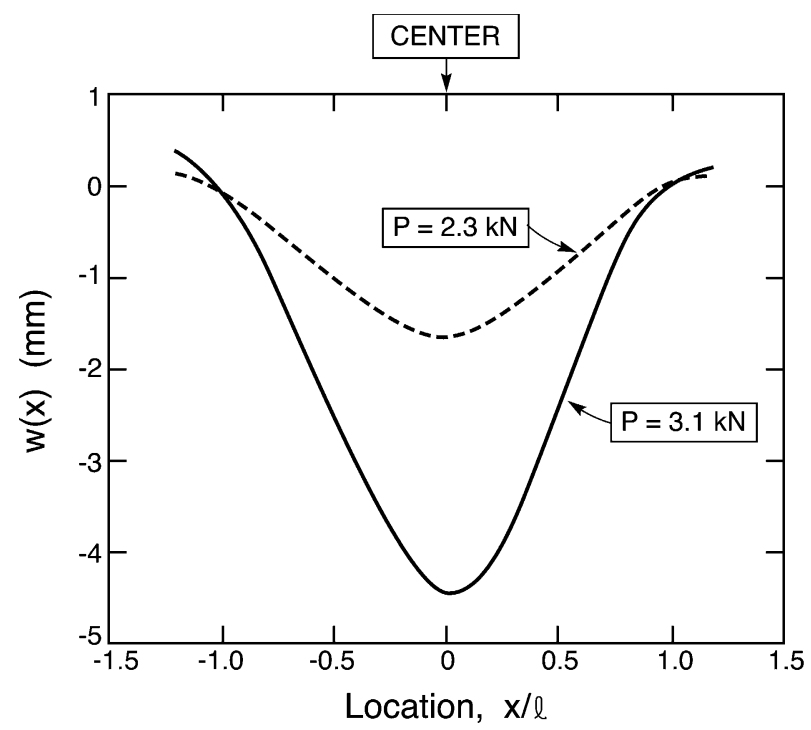

Fig. 19. The calculated deflections of the panel in bending, presented at two of the load levels from Fig. 18. 


\section{Interpretation}

\subsection{Analytical}

The stress/strain response for the alloy (Fig. 7) is used as input to the formulae in Appendix A in order to predict properties that can be compared with the measured values. The bending stiffness, $S_{\mathrm{B}}$, is determined by evaluating the shear modulus of the core, $G^{\mathrm{c}}$, from (A.5) and inserting into the Timoshenko beam theory result (A.9). The measured stiffness values exceed these predictions (Fig. 12), again exposing the limitations of this version of beam theory (Bart-Smith et al., 2001).

Assessment of the limit load, $P_{\max }$ is performed in the following manner. When the failure occurs by core shear, the contribution of the core to $P_{\max }$ is obtained by evaluating $\tau_{\mathrm{Y}}^{\mathrm{c}}$ from (A.6), upon equating $\sigma_{\mathrm{Y}}^{\text {core }}$ to the stress for plastic buckling, $\sigma_{\mathrm{pb}}$ (A.8), upon assuming fully-clamped end conditions. To determine the contribution of face yielding, the strain at which the load attains the maximum (Fig. 13) is superposed on the stress/strain curve (Fig. 7) and the associated flow stress taken as $\sigma_{\mathrm{Y}}^{\text {face }}$. With these specifications for $\sigma_{\mathrm{Y}}^{\text {core }}$ and $\sigma_{\mathrm{Y}}^{\text {face }}$, the load maximum may be estimated from (A.10a) and (A.10b), with and without hinges. The load maxima calculated in this way are compared with the measured values, both in Table 1 and in Fig. 9 (using averages from Table 1). The corresponding results for failure by face yielding are determined from (A.11) upon using the same procedure for determining $\sigma_{\mathrm{Y}}^{\text {face }}$. The correspondence is seen to be quite good. The most significant discrepancy occurs for the largest diameter truss in the sense that, whereas core yielding is the expected failure mode, it actually fails by face yielding at a smaller load than predicted.

The maximum stress needed to crush the core is obtained by again using the stress for plastic buckling $\sigma_{\mathrm{pb}}$ (A.7), determined for the same end conditions, and inserting into the result for the compressive strength (A.7) for the appropriate relative density. This predicts a peak stress, $P_{\text {crush }}=4.3 \mathrm{MPa}$, somewhat smaller than the measured value, $P_{\text {crush }}=4.8 \mathrm{MPa}$ (Fig. 15).

The shear results are assessed using (A.5) governing the shear modulus and (A.6) dictating the shear strength, with (A.8) as the effective inelastic strength, $\sigma_{\mathrm{Y}}^{\text {core }}$, in the negative orientation. The modulus is ascertained from performing a curve fit on the load curve and using the linear coefficient. The comparison is summarized on Table 1. Note that the measured shear modulus is entirely consistent with (A.5). Moreover, the shear yield strength measured in the negative orientation is similar to that predicted by (A.6). In the positive orientation, (A.6) underestimates the measured strength when the offset yield strength is used for $\sigma_{\mathrm{Y}}^{\text {core }}$, because the effect of strain hardening has not been included. The correspondence is much improved when the hardening is introduced, as elaborated in the next section.

\subsection{Comparison with numerical simulations}

The comparison between the measured and calculated shear response for the core is presented in Fig. 14. The shear modulus ascertained from the unloading measurements is in close agreement with the calculated

Table 1

Comparison of calculated and measured limit loads and shear moduli

\begin{tabular}{lllllll}
\hline $\begin{array}{l}\text { Truss radius } \\
(\mathrm{mm})\end{array}$ & $\begin{array}{l}\text { Predicted limit load due to } \\
\text { core shear }(\mathrm{MPa})\end{array}$ & $\begin{array}{l}\text { Predicted lim- } \\
\text { it load due to } \\
\text { face yielding } \\
(\mathrm{MPa})\end{array}$ & $\begin{array}{l}\text { Measured } \\
\text { limit load } \\
(\mathrm{MPa})\end{array}$ & $\begin{array}{l}\text { Calculated } \\
\text { shear modu- } \\
\text { lus (MPa) }\end{array}$ & $\begin{array}{l}\text { Measured shear modulus } \\
(\mathrm{MPa})\end{array}$ & $\begin{array}{l}\text { Positive } \\
\text { Without }\end{array}$ \\
\hline 0.58 & 3280 & 3480 & 7110 & 3870 & 323 & 337 \\
0.69 & 4790 & 5200 & 8970 & 4680 & & 323 \\
0.83 & 6810 & 7630 & 9680 & 7260 & & Negative \\
\hline
\end{tabular}


level. Moreover, the maximum shear forces, as well as the (positive/negative orientation) asymmetry found in the experiments, are accurately duplicated in the calculations. The only disparity is the lower strain hardening obtained in the measurements relative to the calculations. The origin is uncertain, but is tentatively attributed to the difficulty in preventing some rotation at the nodes in the present experimental arrangement (Fig. 10).

A comparison between the simulated load/deflection behavior in three-point bending with the curve measured for the same panel is presented in Fig. 18. The simulation slightly underestimates the stiffness, but appreciably underestimates the strength until the deflection becomes large $(8-10 \mathrm{~mm})$. This discrepency is attributed to the significant lateral constraint exerted by the supports during bending. While this constraint does not affect results in the linear range, as deflections grow, a stretching force develops in the lower face sheet that is not accounted for in the analysis. Note that the present model has not incorporated the fall-off in core shear expected after buckling is well under way, and therefore does not predict the decline in load at large deflections.

\section{Conclusion}

The present series of experiments validates the performance of truss core panels with tetrahedral coordination, in near-optimum designs. The creation of a "gap node" design, through a rapid prototyping approach, followed by investment casting, has been a critical element in demonstrating the full potential of the truss core panel. This node design has enabled the stiffness to attain expected levels and has suppressed undesirable failure modes (Deshpande et al., 2001).

Choosing an alloy that has high ductility when tested in uniaxial tension (greater than about 20\%) appears to be necessary if the panel is to achieve its full load carrying potential. This ductility requirement appears to be related to the development of high-hydrostatic stress concentrations near the nodes and the presence of casting porosity in the same vicinity. This finding highlights the challenges in manufacturing high performance panels by casting and points toward alternate approaches based on wrought materials, such as woven systems (Sypeck et al., 2001).

The present study has highlighted the substantial differences that arise in the responses of trusses that experience tension relative to those in compression. The trusses in tension continue to strain harden beyond yield, such that the load capacity of a panel increases as it shears. Conversely, the trusses in compression exhibit buckling after a small plastic strain, limiting the load capacity. This effect has been most vividly illustrated on panels tested in bending. In such tests, the panel response is asymmetric despite the fact that the trusses yield in the same manner on both sides.

\section{Appendix A}

Analytical results for truss cores and panels (Wicks and Hutchinson, 2001; Deshpande et al., 2001; Deshpande and Fleck, 2001; Ashby et al., 2000; Gibson and Ashby, 1997).

\section{A.1. Basic characteristics}

For the type A panels (Fig. 1a), upon application of a shear force, $V$, the trusses designated $\mathrm{AA}^{\prime}$ experience the largest axial stresses, given by (Wicks and Hutchinson, 2001; Deshpande et al., 2001):

$$
\sigma_{\mathrm{c}}= \pm \frac{\sqrt{3} L_{\mathrm{c}} d}{\pi H_{\mathrm{c}} R_{\mathrm{c}}^{2}},
$$


where $d=\sqrt{L_{\mathrm{c}}^{2}-H_{\mathrm{c}}^{2}}$, with $L_{\mathrm{c}}$ the truss length, $R_{\mathrm{c}}$ its radius and $H_{\mathrm{c}}$ the core thickness. The positive and negative orientations are depicted on Figs. $1 \mathrm{~b}$ and 14. The transverse shear stiffness in this orientation is (Wicks and Hutchinson, 2001; Deshpande et al., 2001):

$$
S_{\mathrm{c}}=\frac{\pi E R_{\mathrm{c}}^{2} H_{\mathrm{c}}^{2}}{\sqrt{3} L_{\mathrm{c}}^{3}} .
$$

The stress in the faces is:

$$
\sigma_{\mathrm{f}}= \pm \frac{M}{t_{\mathrm{f}} H_{\mathrm{c}}},
$$

where $M$ is the bending moment $(M=\ell V$, where $\ell$ is the span).

\section{A.2. Core properties}

The preceding results can be used to determine the response of the core, upon relating its dimensions to the relative density, $\bar{\rho}_{\text {core }}$, using (Deshpande et al., 2001),

$$
\bar{\rho}_{\text {core }}=\frac{6 \pi R_{\mathrm{c}}^{2}}{\sqrt{3} L_{\mathrm{c}} H_{\mathrm{c}}} .
$$

The transverse shear modulus of the panel, $G^{\mathrm{c}}$, is obtained from (A.2) and (A.4) as (Deshpande et al., 2001):

$$
\frac{G^{\mathrm{c}}}{E}=\frac{1}{6}\left(\frac{H_{\mathrm{c}}}{L_{\mathrm{c}}}\right)^{2} \bar{\rho}_{\text {core }} .
$$

The shear yield strength of the core, $\tau_{\mathrm{Y}}^{\mathrm{c}}$, is obtained upon equating the stresses in the truss (A.1) to the yield condition for the trusses $\left(\sigma_{\mathrm{c}} \equiv \sigma_{\mathrm{Y}}^{\text {core }}\right)$ (Deshpande et al., 2001):

$$
t_{\mathrm{Y}}^{\mathrm{c}} \sigma_{\mathrm{Y}}^{\mathrm{core}}=\left(\frac{H_{\mathrm{c}}}{6 d}\right) \bar{\rho}^{\mathrm{core}}
$$

The corresponding compressive strength, $\sigma_{\mathrm{Y}}^{\mathrm{c}}$, is (Deshpande et al., 2001):

$$
\frac{\sigma_{\mathrm{Y}}^{\mathrm{c}}}{\sigma_{\mathrm{Y}}^{\text {core }}}=\left(\frac{H_{\mathrm{c}}}{L_{\mathrm{c}}}\right)^{2} \bar{\rho}_{\text {core }} .
$$

For cases wherein the most highly stressed trusses are compressed and buckle plastically, $\sigma_{\mathrm{Y}}^{\text {core }}$ becomes the collapse stress, $\sigma_{\mathrm{pb}}$, given by the implicit formula (Deshpande et al., 2001):

$$
\left(\frac{\pi k R_{\mathrm{c}}}{2 L_{\mathrm{c}}}\right)^{2} \varepsilon_{\mathrm{Y}}^{-1}=\left(\frac{\sigma_{\mathrm{pb}}}{\sigma_{\mathrm{Y}}}\right)+\alpha N\left(\frac{\sigma_{\mathrm{pb}}}{\sigma_{\mathrm{Y}}}\right)^{N},
$$

where $k$ is a measure of the rotational stiffness of the nodes (it ranges between 1 and 2), with $\alpha, N, \varepsilon_{Y}$ determined from the Ramberg-Osgood expression for the stress/strain curve (4.1).

\section{A.3. Panel properties}

The results for the core can be used to determine the bending properties of panels. The bending stiffness, $S_{\mathrm{B}}$, is given by (Ashby et al., 2000; Gibson and Ashby, 1997): 


$$
\frac{1}{S_{\mathrm{B}}}=\frac{2 \ell^{3}}{C_{1} b E t_{\mathrm{f}} c^{2}}+\frac{H_{\mathrm{c}} \ell}{C_{2} b c^{2} G^{\mathrm{c}}},
$$

where $b$ is the panel width, $c=H_{\mathrm{c}}+t_{\mathrm{f}}$, and, for three-point bending, $C_{1}=48$ and $C_{2}=4$. Substituting $G^{\mathrm{c}}$ from (A.5) into (A.9) gives $S_{\mathrm{B}}$.

The limit load $P_{\max }\left(V_{\max } / 2\right)$ depends on whether the panel fails by face yielding or core shear. When core shear predominates, the response at the outer supports has an important influence. If plastic hinges develop, such that the overhang does not contribute to that portion of the load carried by the core, then (Ashby et al., 2000):

$$
P_{\max }^{\text {core }}=\frac{4 b t_{\mathrm{f}}^{2} \sigma_{\mathrm{Y}}^{\mathrm{face}}}{\ell}+2 b c \tau_{\mathrm{Y}}^{\mathrm{c}}
$$

The first term is the contribution from the plastic hinges formed in the faces and the second due to shear yielding of the truss core. Substituting $\tau_{\mathrm{Y}}^{\mathrm{c}}$ from (A.6) into (A.10a) and (A.10b) predicts the limit load. Absent hinges at the supports, the corresponding result is (Ashby et al., 2000):

$$
P_{\max }^{\text {core }}=\frac{2 b t_{\mathrm{f}}^{2} \sigma_{\mathrm{Y}}^{\text {face }}}{\ell}+2 b c \tau_{\mathrm{Y}}^{\mathrm{c}}\left[1+2 H_{\mathrm{over}} / \ell\right]
$$

where $H_{\text {over }}$ is the overhang (see Fig. 3). When the panel fails by face yielding, the limit load is (Ashby et al., 2000):

$$
P_{\max }^{\mathrm{face}}=\frac{4 b t_{\mathrm{f}}\left(c+t_{\mathrm{f}}\right) \sigma_{\mathrm{Y}}^{\mathrm{face}}}{\ell}+\frac{b c^{2} \sigma_{\mathrm{Y}}^{\mathrm{c}}}{\ell}
$$

with $\sigma_{\mathrm{Y}}^{\mathrm{c}}$ obtained from (A.7).

\section{References}

Ashby, M.F., Evans, A.G., Fleck, N.A., Gibson, L.J., Hutchinson, J.W., Wadley, H.G.N., 2000. Metal Foams: a Design Guide. Butterworth-Heinemann, Boston.

Bart-Smith, H., Hutchinson, J.W., Evans, A.G., 2001. Measurement and analysis of the structural performance of cellular metal sandwich construction. Int. J. Mech. Sci. 43, 1945.

Budiansky, B., 1999. On the minimum weights of compression panels. Int. J. Solids Struct. 36, 3677-3708.

Crump, S., 1992. U.S. Patent \#5121329.

Deshpande, V., Fleck, N.A., Ashby, M.F., 2001. Effective properties of the octet-truss lattice material. J. Mech. Phys. Solids.

Deshpande, V.S., Fleck, N.A., 2001. Collapse of truss core sandwich beams in 3-point bending. Int. J. Solids Struct. $38,6275$.

Evans, A.G., Hutchinson, J.W., Ashby, M.F., 1998. Multifunctionality of cellular metal systems. Progr. Mater. Sci. 43, $171-221$.

Evans, A.G., Hutchinson, J.W., Fleck, N.A., Ashby, M.F., Wadley, H.G.N., 2001. The topological design of multifunctional cellular metals. Progr. Mater. Sci. 46, 311-327.

Fuller, R.B., 1961. U.S. Patent 2,986,241.

Gibson, L.J., Ashby, M.F., 1997. Cellular Solids: Structure and Properties, second ed. Cambridge University Press, New York.

Karlsson, A., Hyun, S., 2001, unpublished research.

Sypeck, D.J., Wadley, H.G.N., 2001. Multifunctional microtruss laminates: textile synthesis and properties. J. Mater. Res. 16, 890897.

Wallach, J.C., Gibson, L.G., in press. Mechanical behavior of a three-dimensional truss material. Int. J. Solids Struct.

Wicks, N., Hutchinson, J.W., 2001. Optimal truss plates. Int. J. Solids Struct. 38, 5165. 